\title{
A BIBLIOTECA UNIVERSITÁRIA HÍBRIDA COMO ESPAÇO DE MEMÓRIA
}

\author{
Rubens da Costa Silva Filho ${ }^{1}$
}

\begin{abstract}
RESUMO: As bibliotecas universitárias resguardam os conhecimentos gerados nas instituições de ensino onde estão inseridas, além disso, reúnem, organizam e disseminam as produções de cunho cultural e técnico-científico no âmbito de suas instituições. A biblioteca universitária caracteriza-se como espaço da memória científica dentro de uma universidade, pois é o local onde é reunida a produção científica gerada na instituição. Além de preservar a memória das universidades, a biblioteca proporciona a multiplicação do conhecimento gerando através de seu acervo novos conhecimentos. Os espaços de memória como bibliotecas, museus e arquivos devem se adaptar aos novos tempos, proporcionando novas formas de reunir, organizar e promover a memória das instituições, dos grupos e dos indivíduos.
\end{abstract}

Palavras-chave: Espaço de memória. Biblioteca universitária. Biblioteca híbrida. Repositórios institucionais.

\section{THE HYBRID UNIVERSITY LIBRARY AS A MEMORY SPACE}

\begin{abstract}
The university libraries safeguard the knowledge generated in the educational institutions where they are inserted. In addition, they gather, organize and disseminate cultural and technical-scientific productions within their institutions. The university library is characterized as a space of scientific memory within a university, because it is the place where the scientific production generated in the institution is gathered. In addition to preserving the memory of universities, the library provides the multiplication of knowledge generating through its collection new knowledge. Memory spaces such as libraries, museums and archives should adapt to new times, providing new ways of bringing together, organizing and promoting the memory of institutions, groups and individuals.
\end{abstract}

Keywords: Memory space. University library. Hybrid library. Institutional repositories.

\section{INTRODUÇÃO}

As bibliotecas como espaços de memória remontam ao século III a.C., com a fundação da maior biblioteca do mundo antigo, a Biblioteca de Alexandria. Esta biblioteca tinha como missão acumular todo o conhecimento humano produzido na antiguidade. Além de suas funções de acumulação e preservação de todo saber humano, a Biblioteca de Alexandria era um importante lugar de socialização, disseminação do saber e construção de novos conhecimentos (GOULEMOT, 2011, p.37).

As bibliotecas desde então possuem um caráter social onde se inserem as funções de preservação, organização e disseminação das produções humanas. Silveira (2012) afirma que as bibliotecas enquanto "lugares de memória” tendem a reafirmar os saberes e a torná-los móveis, traduzíveis e permutáveis. Estas instituições nos permitem o acesso por meio de seus acervos, ao conhecimento gerado pela humanidade, assim como fornecer os insumos às necessidades e os intentos de cada um de seus usuários em particular.

\footnotetext{
${ }^{1}$ Doutorando em Comunicação e Informação pela Universidade Federal do Rio Grande do Sul (UFRGS). Mestre em memória Social e Bens Culturais pela Universidade La Salle (UNILASALLE).
} 


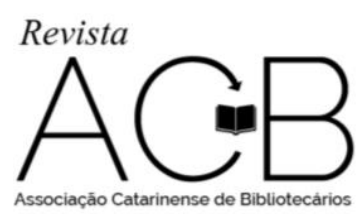

Revista ACB: Biblioteconomia em Santa Catarina, Florianópolis, v. 23, n. 1, p. 21-36, dez./mar., 2018.

Para Jacob (2000) a biblioteca é vista como: Lugar da memória nacional, espaço da conservação do patrimônio intelectual, literário e artístico, uma biblioteca é também o teatro de uma alquimia complexa em que, sob o efeito da leitura, da escrita e de sua interação, se liberam as forças, os movimentos do pensamento. É um lugar de diálogo com o passado, de criação e inovação, e a conservação só tem sentido como fermento dos saberes e motor do conhecimento, a serviço da coletividade inteira.

Com o advento da escrita e posteriormente com a invenção da imprensa a produção de informações aumentou exponencialmente, o que acabou por favorecer a criação de arquivos, bibliotecas e museus ou instituições-memória, como propôs Le Goff (2003). De acordo com Monteiro, Carelli e Pickler (2008), o uso da escrita permitiu que fosse registrada toda memória do cérebro humano permitindo que tudo fosse passível de ser lembrado, uma vez que as memórias pudessem ser registradas e preservadas.

Thiesen (2009) afirma que se a memória age como uma presentificação do passado e, se a sua materialidade, o documento em si é perdido ou está fora do lugar onde deveria estar para abrigá-lo, perdese a evocação do passado, não sendo possível o seu acesso nem pela via da memória, nem pela mão da história. A autora segue afirmando que os lugares de memória acabam por refletir uma memória enquadrada proporcinando uma quebra de silêncio, onde a memória será plural, mas contraditória, inacabada e sempre sujeita a flutuações.

A memória é o cerne da existência de instituições-memória, como as bibliotecas. De acordo com Costa (1997), a memória é um elemento primordial no funcionamento das instituições. Através da memória as instituições se reproduzem no seio da sociedade, retendo apenas as informações que interessam ao seu funcionamento. No âmbito destas instituições ocorre um processo seletivo do que deve ser retido e que se desenvolve segundo regras instituídas e que variam de instituição para instituição.

Este trabalho possui como objetivo verificar se há indícios na literatura científica que permitam identificar se as bibliotecas universitárias atualmente, numa matriz híbrida, como espaços de memória representativos das instituições e comunidades acadêmicas a que atendem.

\section{BIBLIOTECAS COMO ESPAÇOS DE MEMÓRIA}

Nas bibliotecas o processo de seleção das informações e documentos que devem ser retidos ou descartados é de suma importância. As bibliotecas universitárias resguardam os conhecimentos gerados nas instituições de ensino onde estão inseridas, além disso, reúnem, organizam e disseminam as produções de cunho cultural e técnico-científico no âmbito de suas instituições. O documento como produto da memória 


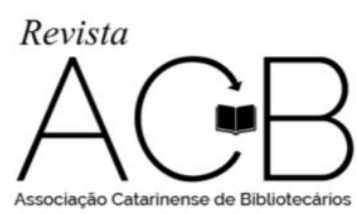

Revista ACB: Biblioteconomia em Santa Catarina, Florianópolis, v. 23, n. 1, p. 21-36, dez./mar., 2018.

Antes de entendermos a biblioteca como espaço de memória é necessário entender o conceito de documento como objeto de memória. Le Goff (1990) afirma que um objeto de memória pertence à categoria de documento/monumento. Como documento, este objeto não é apenas algo do passado e sim um produto da sociedade da época que o fabricou, de acordo com as relações de forças que à época detinham poder. Ainda para Le Goff (1990, p. 535) estes materiais da memória “podem apresentar-se sob duas formas principais: monumentos, como uma herança do passado, e os documentos, como escolha do historiador”. Nora (1993, p. 22) afirma que:

[...] lugares mistos, híbridos e mutantes, intimamente enlaçados de vida e de morte, de tempo e de eternidade; numa espiral do coletivo e do individual, do prosaico e do sagrado, do imóvel e do móvel. [...] enrolados sobre si mesmos. Porque, se é verdade que a razão fundamental de ser de um lugar de memória é parar o tempo, é bloquear o trabalho do esquecimento, fixar um estado de coisas, imortalizar a morte, materializar o imaterial para prender o máximo de sentido num mínimo de sinais, é claro, e é isso que os torna apaixonantes: que os lugares de memória só vivem de sua aptidão para a metamorfose, no incessante ressaltar de seus significados e no silvado imprevisível de suas ramificações.

Para Dodebei (1997), o livro já nasce com a idéia de memória, não da ordem institucional, mas intelectual, uma vez que os livros são a síntese do objeto e do relato. Já Foucault (1997) entende que o documento:

[...] (livros, textos, narrações, registros, atas, edifícios, instituições, regulamentos, técnicas, objetos, costumes etc.) não é o feliz instrumento de uma história que seja, em sí própria e com pleno direito, memória: a história é uma certa maneira de uma sociedade dar estatuto e elaboração a uma massa documental, de que não se separa.

Para construir o conceito de documento, Dodebei (1997), sugere três proposições, às quais:

a) UNICIDADE: nesta proposição os documentos que são os objetos de estudo da memória social não são diferenciados em sua essência ou seja, não se agrupam em categorias específicas, tal como os exemplos tradicionais: o livro para bibliotecas, o objeto tridimensional para museus e o manuscrito para arquivos;

b) VIRTUALIDADE: onde a atribuição de predicáveis ao objeto submetido ao observador dentro das dimensões espaço-tempo é seletiva, o que proporcionará, arbitrariamente, uma classificação desse objeto;

c) SIGNIFICAÇÃO: quando ocorre a transformação dos objetos do cotidiano em documentos é intencional, constituindo estes uma categoria temporária e circunstancial. 
O documento em si não deve ser reduzido apenas a sua forma e seu caráter informacional, e sim ser encarado como uma forma de fomentar e preservar a memória social (DODEBEI, 1997). O documento é tema central das áreas de Arquivologia, Biblioteconomia e Museologia, onde há em comum entre elas os processos de identificação, descrição e comunicação do conteúdo informacional dos mesmos, como ilustra Dodebei (2011), na Figura 1:

Figura 1 - Preservação dos documentos em instituições de memória

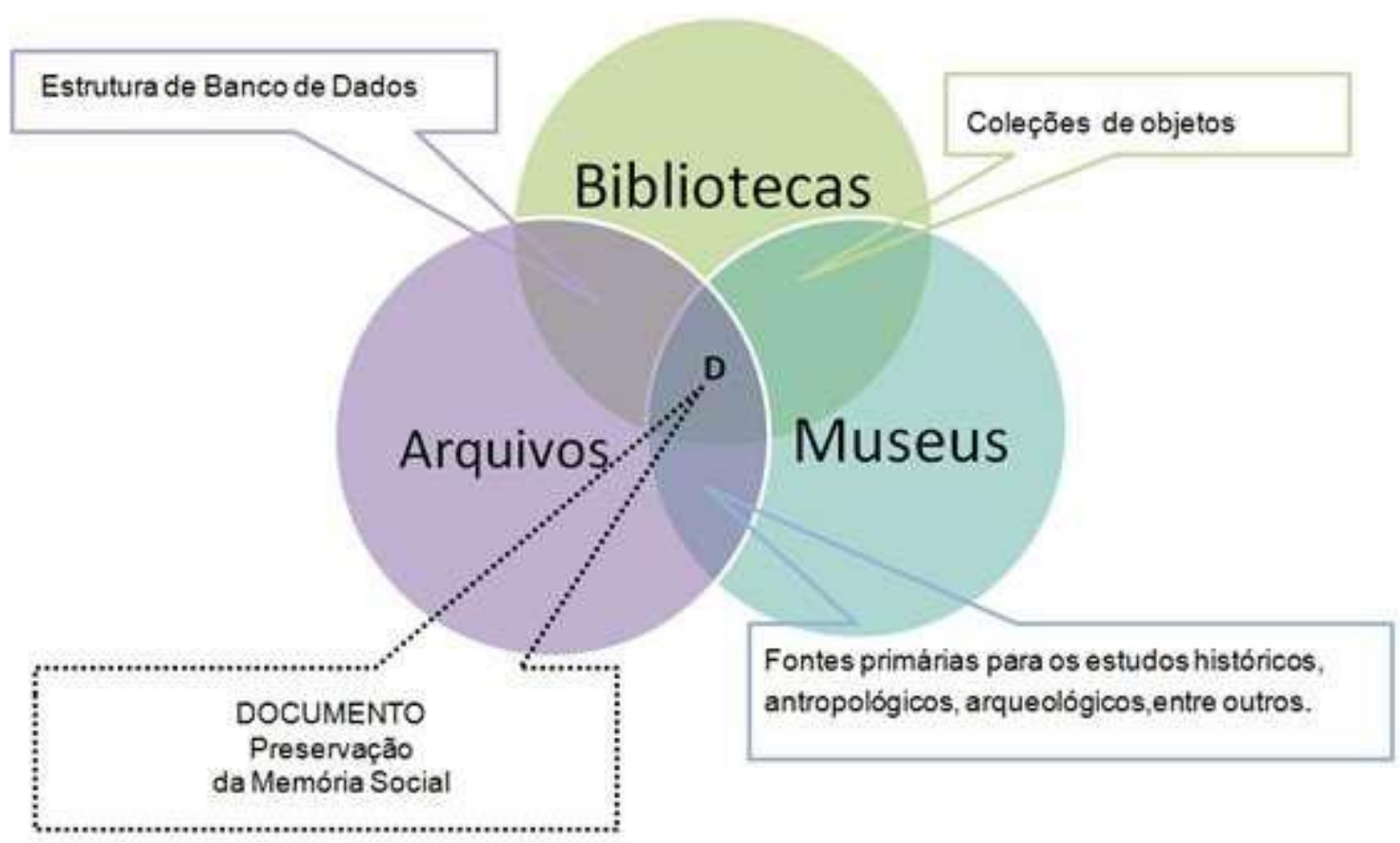

Fonte: Dodebei (2011).

Para Nora (1993), o significado da existência de "museus, arquivos, cemitérios ecoleções, festas, aniversários, tratados, processos verbais, monumentos, santuários, associações são os marcos testemunhas de uma outra era, das ilusões da eternidade". Este autor afirma que os lugares de memória são nada mais que lugares de restos de memória. O mesmo Nora entende ainda que os lugares de memória

[...] nascem e vivem do sentimento que não há memória espontânea, que é preciso criar arquivos, que é preciso manter aniversários, organizar celebrações, pronunciar elogios fúnebres, notariar atas, porque essas operações não são naturais. (NORA, 1993, p. 13).

Já Dodebei (1997) propõe outra linha de raciocínio, ela entende que se o conceito de memória é reter fatos passados, então as bibliotecas e os arquivos cumprem a tarefa de preservação da memória. 


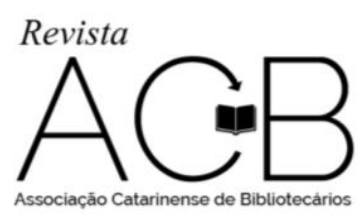

Revista ACB: Biblioteconomia em Santa Catarina, Florianópolis, v. 23, n. 1, p. 21-36, dez./mar., 2018.

A transcendência da memória e do conhecimento humano é materializada nas bibliotecas, uma vez que estas se propõe além da preservação, a disseminação do conhecimento contido em seu acervo:

[...] as bibliotecas abandonam seu estereótipo de depósito do conhecimento para se exibirem como "lugares de memória", de tradição, de práticas culturais. Em resumo: como espaços onde nosso patrimônio material e imaterial é captado, preservado e disseminado. (SILVEIRA, 2012).

De acordo com Namer (1987), as instituições de memória são aquelas formadas pela memória individual, coletiva ou social, em que se diferem dos lugares de memória que segundo o autor servem apenas para a rememoração individual ou coletiva.

O acesso à memória nas bibliotecas se dá a partir do seu catálogo, que funciona como um guia até o lugar onde se encontra o documento. Esta busca pelo documento poderá se dar em meio físico com o uso de fichários ou por meio virtual através de catálogos virtuais que lhe proporcionarão o acesso ao documento na íntegra ou sua localização em um acervo físico.

A importância das bibliotecas como espaço de memória e representatividade no seio de uma sociedade é constatada por Oliveira e Santos (2009), onde A possibilidade do saber e do amadurecimento científico e humano através da aprendizagem tem na Biblioteca um grande símbolo. A quantidade e variedade de livros que estão nela compilam muitos dos resultados da caminhada intelectual da humanidade: as descobertas, os inventos e os escritos, que impulsionaram o desenvolvimento, promoveram o contentamento ou o sofrimento; enfim, tudo que mereceu ou que pôde ser anotado e que, portanto, recebeu a imortalidade, reunido e arquivado num único espaço físico, porém, ilimitado, como imaginamos que seja "um" universo. A relevância social das bibliotecas como lugares de memória é retratada por Jacob (2000, p. 11) em que:

[...] a história das bibliotecas no Ocidente é indissociável da história da cultura e do pensamento, não só como lugar de memória no qual se depositam os estratos das inscrições deixadas pelas gerações passadas, mas também como espaço dialético no qual, a cada etapa dessa história, se negociam os limites e as funções da tradição, as fronteiras do dizível, do legível e do pensável, a continuidade das genealogias e das escolas, a natureza cumulativa dos campos de saber ou suas fraturas internas e suas reconstruções.

Para Ribeiro (2010) a biblioteca é um espaço onde a leitura questiona e a memória social responde. Nas bibliotecas, os bibliotecários tem a função de mediar a relação do documento/informação com seu pesquisador, facilitando o acesso da informação a quem necessita. Para Chartier (2002) as bibliotecas são 


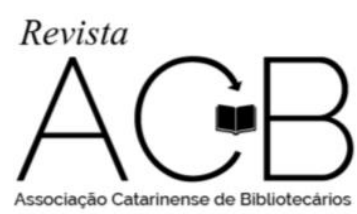

Revista ACB: Biblioteconomia em Santa Catarina, Florianópolis, v. 23, n. 1, p. 21-36, dez./mar., 2018.

como espaços dinâmicos e vivos que possuem entre outras tarefas fundamentais colecionar, [...], inventariar e, posteriomente, tornar acessível a herança da cultura escrita. No livro se expressa uma vontade de memória que se atualiza através da leitura. Quando ele se fecha, a memória torna-se novamente virtual (RIBEIRO, 2010).

A biblioteca universitária caracteriza-se como espaço da memória científica dentro de uma universidade, pois é nela que identifica-se como o local onde é reunida a produção científica gerada na instituição. Além de preservar a memória das universidades, a biblioteca proporciona a multiplicação do conhecimento gerando através de seu acervo novos conhecimentos. Segundo Crippa (2010, p. 98) a construção da memória científica:

[...] é de natureza "evolutiva", positiva, com a eliminação do passado enquanto redundante. $\mathrm{O}$ que constitui um saber aceito, validado pela comunidade científica é integrado e não precisa mais ser discutido. Selecionam-se elementos que representam os "avanços" enquanto a idéia de "progresso" leva até à remoção de livros e revistas considerados ultrapassados no âmbito das bibliotecas especializadas: encontrada a solução dos problemas, as tentativas e erros anteriores são eliminadas como "peso inútil". O esquecimento não é somente inevitável, mas é um ato validado enquanto necessário para prosseguir.

A Ciência da Informação, que se constitui pela Museologia, Arquivos e a Biblioteconomia, é responsável por fazer a reflexão sobre os processos de seleção, organização e disseminação dos produtos atuais do conhecimento, fontes de memória futura, tanto no campo humanista, bem como científico (CRIPPA, 2010).

No Brasil, a Biblioteca Nacional (BN) é responsável pela guarda te toda produção bibliográfica nacional. Todas as editoras do país devem, por força de lei remeterem um exemplar de cada obra publicada à Biblioteca Nacional, o chamado "Depósito Legal", tendo como missão assegurar a coleta, a guarda e a difusão da produção intelectual brasileira, objetivando à preservação e a formação da Coleção Memória Nacional. Além do depósito legal de publicações na Biblioteca Nacional, esse repasse tem como propósito o registro e a guarda da produção intelectual nacional, possibilitando o controle, a elaboração e a divulgação da bibliografia brasileira corrente e proporcionando a defesa e a preservação da língua e cultura nacionais.

Os conhecimentos científicos, técnicos, artísticos e administrativos gerados no âmbito das universidades são denominados como produção intelectual. Essa produção intelectual é produzida pelos docentes, discentes e técnico-administrativos que nela estudam, pesquisam e trabalham. 


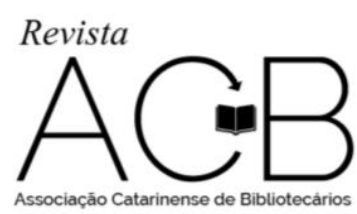

Revista ACB: Biblioteconomia em Santa Catarina, Florianópolis, v. 23, n. 1, p. 21-36, dez./mar., 2018.

A preservação da memória da universidade ou de uma faculdade específica, pode ser entendida como o fomento da memória coletiva dessas instituições, de grupos e indivíduos que dela usufruíram. A memória coletiva é definida pelo dicionário E-mnemon (2011) como:

[...] as interações possíveis entre as políticas da memória - a memória histórica e social sendo concebida como uma relação de forças que resulta em definições e redefinições do que é considerado como passado e heranças comuns de um dado grupo ou classe social - e as lembranças de fatos vividos em comum ou individualmente. Nesse sentido, a memória coletiva se situa no encontro entre o individual e o coletivo, entre o psíquico e o social.

Devido à obrigatoriedade de manter as produções realizadas pela universidade, as bibliotecas acabam por se defrontarem com o problema de armazenagem dessas produções. Uma vez que o crescimento destas coleções é infinita é mais que necessário o advento de tecnologias da informação para otimizar sua guarda, organização e disponibilização ao público universitário.

Para as bibliotecas universitárias Tammaro e Salarelli (2008), sugerem que a iniciativa de digitalização de documentos de seu acervo apenas em suporte impresso está ligado a um processo de reorganização da comunicação científica e do ensino, construindo bases de conhecimento que ajudam a melhorar a qualidade da educação com redução de seus custos e também abrindo estes documentos que foram digitalizados para um público mais amplo e para novos segmentos de pesquisadores. A digitalização de material didático engloba diferentes tipos de materiais bibliográficos e audiovisuais, como por exemplo: livros, artigos de periódicos, periódicos, filmes, músicas.

\section{A BIBLIOTECA UNIVERSITÁRIAS HÍBRIDAS}

A biblioteca tradicional atualmente já não possui condições de satisfazer as necessidades de seus usuários sem o uso de tecnologias da informação, assim como a biblioteca digital ainda parece uma realidade distante, no curto prazo, devido a ainda predominante publicação de materiais impressos, a coexistência de informações nos formatos impresso e eletrônico, força uma necessidade de adaptação das bibliotecas nesse ínterim, buscando aproveitar e integrar o melhor dos dois formatos.

Segundo Le Coadic (2004) a biblioteca tradicional historicamente composta de produtos informacionais impressos foi sucedida atualmente por centros de informação compostos por acervos contendo os mais diferentes suportes. A incorporação de produtos de informação em suporte eletrônico permitem aos usuários se atualizarem de forma mais ágil, inclusive em tempo real, ampliando assim o 


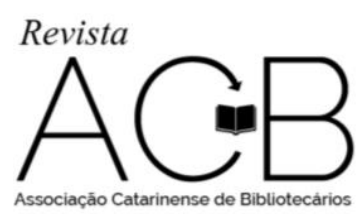

Revista ACB: Biblioteconomia em Santa Catarina, Florianópolis, v. 23, n. 1, p. 21-36, dez./mar., 2018.

acesso informacional anteriormente apenas restrito a obras de um patrimônio legado pelo passado como livros impressos. (LE COADIC, 2004).

Barbosa e Franklin (2011, p. 91) destacam o fenômeno da desmediação que permite uma relativa autonomia do usuário com relação aos serviços de informação tradicionais para acesso a informação, possibilitando que este busque o que for de seu interesse sem a:

[...] interferência do mediador, ou seja, da ajuda de um profissional de informação, cuja função, no processo de busca da informação, é facilitar a inserção do usuário no ambiente dos sistemas de recuperação da informação, sendo que a internet, com as soluções de interatividade, interoperabilidade, hipertextualidade etc., concorre com a desenvoltura para que o fenômeno da desmediação se viabilize. (BARBOSA; FRANKLIN, 2011, p. 91).

De acordo com Monfasani e Curzel (2008), na atualidade a informação encontra-se "em dois espaços de naturezas diferentes", na biblioteca tradicional a existência ao mesmo tempo de materiais impressos, audiovisuais e eletrônicos, e o virtual onde a informação pode ser encontrada em diferentes suportes e plataformas, coexistindo na web.

A necessidade de mudança da biblioteca tradicional para uma nova realidade está condicionada às mudanças sofridas pelos suportes que contém o conhecimento, em que a informação para existir independe de estar contida num suporte físico. (LEVACOV, 1998). Levacov ainda levanta outras questões sobre as mudanças implicadas pelas novidades trazidas pela tecnologia da informação, segundo a autora, o bibliotecário tinha uma profissão ligada a um local (a biblioteca) e a um produto (o livro ou textos impressos), seu público deveria se deslocar até o local do acervo para acessar as informações que necessitavam. A necessidade de um local físico para acesso ao conhecimento é cada vez menos necessário pois, segundo Levacov (1998, p. 16), “[...] estamos começando a viver as 'bibliotecas sem paredes para livros sem páginas". Sendo assim, evidenciam-se os dilemas econômicos e culturais atuais que adquirem uma importância crescente como por exemplo, os métodos de produção, processamento e difusão da memória escrita e audiovisual. (LE COADIC, 2004).

Para Rowley (2002), uma biblioteca multimídia (híbrida) deve conter os diversos formatos que sua comunidade de usuários necessita para comunicação e armazenamento de informações. A biblioteca híbrida deve integrar o acesso a quatro tipos de recursos fazendo uso de tecnologias digitais e incorporando todas as mídias (RUSBRIDGE, 1998): 


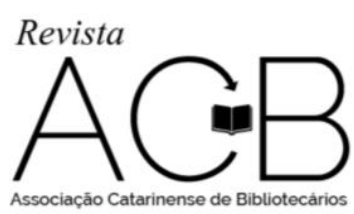

Revista ACB: Biblioteconomia em Santa Catarina, Florianópolis, v. 23, n. 1, p. 21-36, dez./mar., 2018.

a) Recursos tradicionais (Legado): qualquer recurso não digital, não apenas impresso, mas também documentos audiovisuais em suporte magnético, mapas, etc.;

b) Recursos de transição (Transition): recursos tradicionais que estão sendo digitalizados, mediante o uso de OCR assim como técnicas de imaging;

c) Novos recursos (New): recursos informacionais criados especificamente para o suporte digital, e são encontrado em diferentes formatos, tecnologias e sistemas de acesso;

d) Recursos futuros (Future): recursos digitais normalizados, em que os dados e os métodos de acesso formam uma unidade.

Do mesmo modo que Carrion Gútiez (2001), entre a biblioteca tradicional e a biblioteca digital, Tammaro e Salarelli (2008) sugerem um modelo mais adequado à realidade da maioria das bibliotecas que encontramos hoje, a biblioteca híbrida. Este tipo de biblioteca, segundo os autores, possui como característica o manejo de fontes informacionais impressas e eletrônicas, e principalmente a adaptação de seus serviços a um contexto digital, provocando um processo de reengenharia e transformação da biblioteca tradicional.

A biblioteca híbrida também é definida por Garcez e Rados (2002) por agregar diferentes tecnologias e fontes de informação, o que reflete em um estado em que no atual momento não é completamente digital e nem completamente impresso, fazendo uso das tecnologias disponíveis para unir, em uma só biblioteca, “o melhor dos dois mundos (o impresso e o digital)”. Saorín Pérez (2001) relaciona os principais aspectos da biblioteca híbrida:

a) tem origem em uma biblioteca já existente, com seus espaços, coleções, recursos humanos e organizacionais;

b) supõe de um processo já iniciado de integração entre uma biblioteca tradicional com uma digital;

c) os elementos da biblioteca digital surgem para potencializar mais que para substituir a biblioteca convencional existente;

d) o usuário passa a conviver com documentos eletrônicos e em papel;

e) os serviços são produzidos em suportes remotos, sendo sua forma intrínseca a digital, e em suportes físicos, onde também se aplicam as tecnologias digitais;

f) por fim, a biblioteca híbrida afeta não apenas o usuário através da prestação de serviços, mas também o profissional na gestão dos processos da biblioteca. 
O modelo híbrido é determinado pela integração dos serviços da biblioteca e não apenas na existência simultânea de diferentes suportes. Rusbridge (1998) sugere que a biblioteca híbrida deve ser projetada para combinar diferentes tecnologias no contexto de uma biblioteca física e para iniciar novas experiências em sistemas integrados e serviços, tanto no ambiente eletrônico quanto no ambiente físico.

Figura 2 - Bibliotecas quanto as suas características

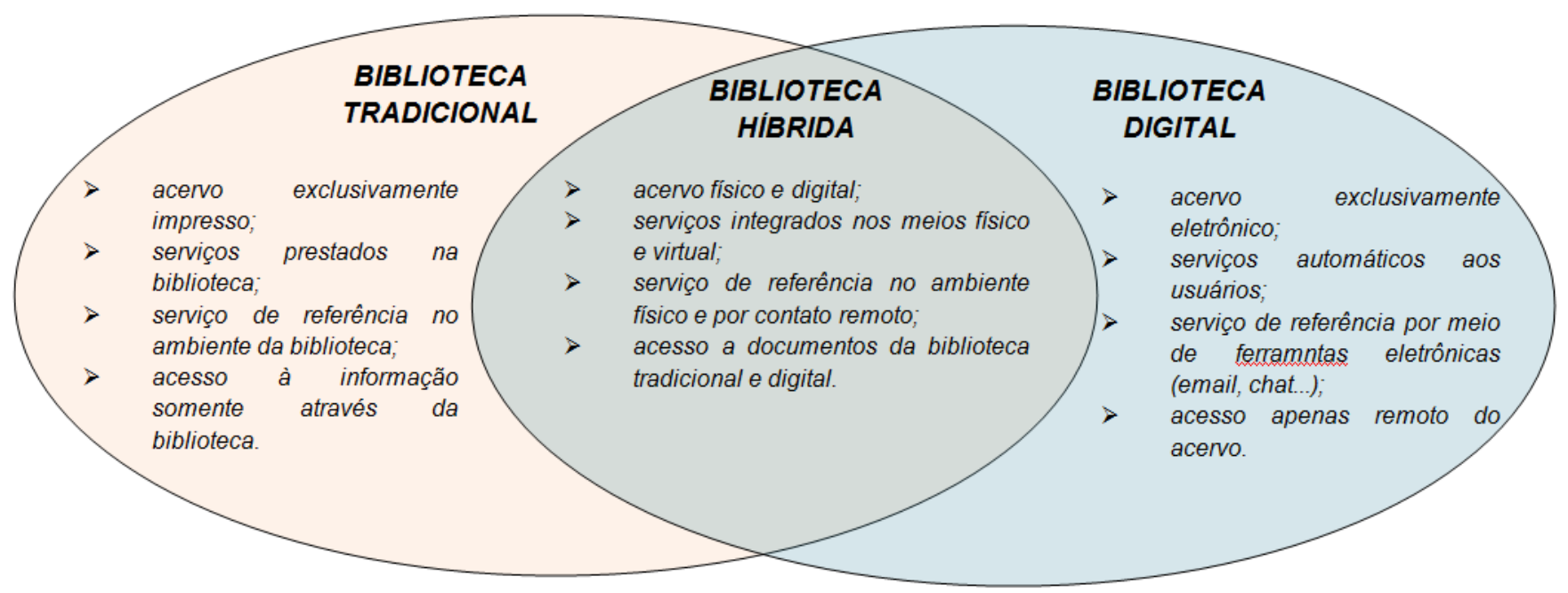

Fonte: dados da pesquisa.

Sobre a integração dos serviços, Garcez e Rados (2002) afirmam que ela proporciona maior flexibilização na oferta de serviços de qualidade adaptados à diversidade de usuários e suas diferentes necessidades de informação, permitindo que a biblioteca agregue valor aos serviços prestados. Os autores sugerem ainda que as bibliotecas busquem identificar grupos de usuários para poder lhes oferecer produtos especializados, pautados por uma prévia avaliação do que eles desejam, e que essa avaliação deve ser feita continuamente.

Como exemplo de adaptação por que passam as bibliotecas universitárias, podemos citar a biblioteca da Universidade de Cambridge, que foi fundada a partir de acervos monacais por volta de 1444, e que hoje disponibiliza mais de 2 mil manuscritos de seu acervo histórico no projeto Cambridge Digital Library, cujas ilustrações se encontram, respectivamente, nas Figuras 3 e 4. 
Figura 3 - Biblioteca híbrida da Universidade de Cambridge

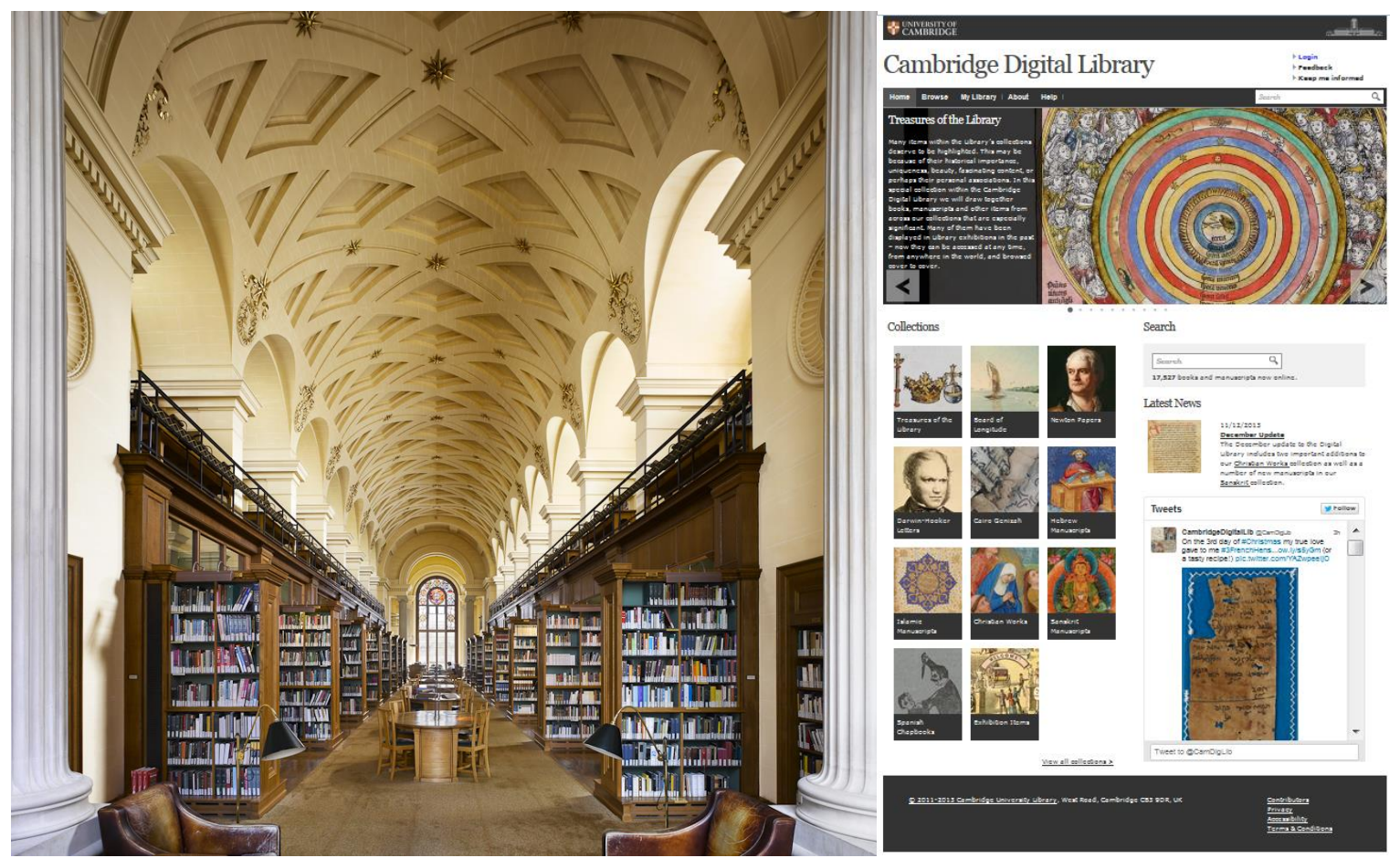

Fonte: University of Cambridge, [2014].

O advento e a popularização dos repositórios institucionais são percebidos por Tammaro e Salarelli (2008) como recursos que possibilitarão grande impacto nos processos de comunicação científica. O problema da preservação da produção científica e da memória institucional é sentido em particular pelas comunidades acadêmicas, em que a qualidade de um trabalho científico é verificada pela quantidade de documentos que o referenciam. Os repositórios institucionais exemplificam duas características essenciais da preservação dos recursos digitais:

a) garantir a qualidade e a autenticidade dos recursos da coleção;

b) identificar o responsável pela preservação a longo prazo. (TAMMARO; SALARELLI, 2008, p. 204).

Como exemplo desta iniciativa podemos citar o repositório institucional da Universidade Federal do Rio Grande do Sul, o LUME, projeto que foi criado em 1995 e é alimentado pelo Sistema de Bibliotecas da Universidade (SBUFRGS). O LUME é um portal que permite o acesso às coleções digitais produzidas no âmbito da Universidade, o repositório possui a missão de reunir, preservar, divulgar e garantir o acesso permanente aos documentos acadêmicos, científicos, artísticos e administrativos gerados 


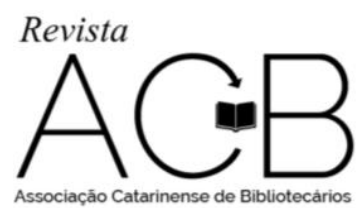

Revista ACB: Biblioteconomia em Santa Catarina, Florianópolis, v. 23, n. 1, p. 21-36, dez./mar., 2018.

na UFRGS, bem como seus documentos históricos ou documentos não criados pela universidade mas de relevância para a instituição. $\mathrm{O}$ acervo do repositório possui diferentes coleções com documentos em diferentes formatos, podendo conter desde textos e imagens até material audiovisual, em sua maioria com acesso livre.

O Lume, segundo dados de 2017, conta em seu acervo eletrônico com aproximadamente 28 mil teses e dissertações, 16 mil trabalhos de conclusão de curso de graduação e 5 mil trabalhos de conclusão de especialização. Além disso, estão disponíveis ainda 15 mil artigos de periódicos; centenas de livros e capítulos de livros, entrevistas, patentes e, ainda, mais de 28 mil trabalhos apresentados em eventos, entre outras produções que promovem além das produções técnicas, científicas e culturais também a memória da própria UFRGS .

Figura 4 - Coleção impressa de teses e dissertações em acervo físico e repositório institucional LUME da UFRGS onde se encontram armazenadas as novas produções acadêmicas

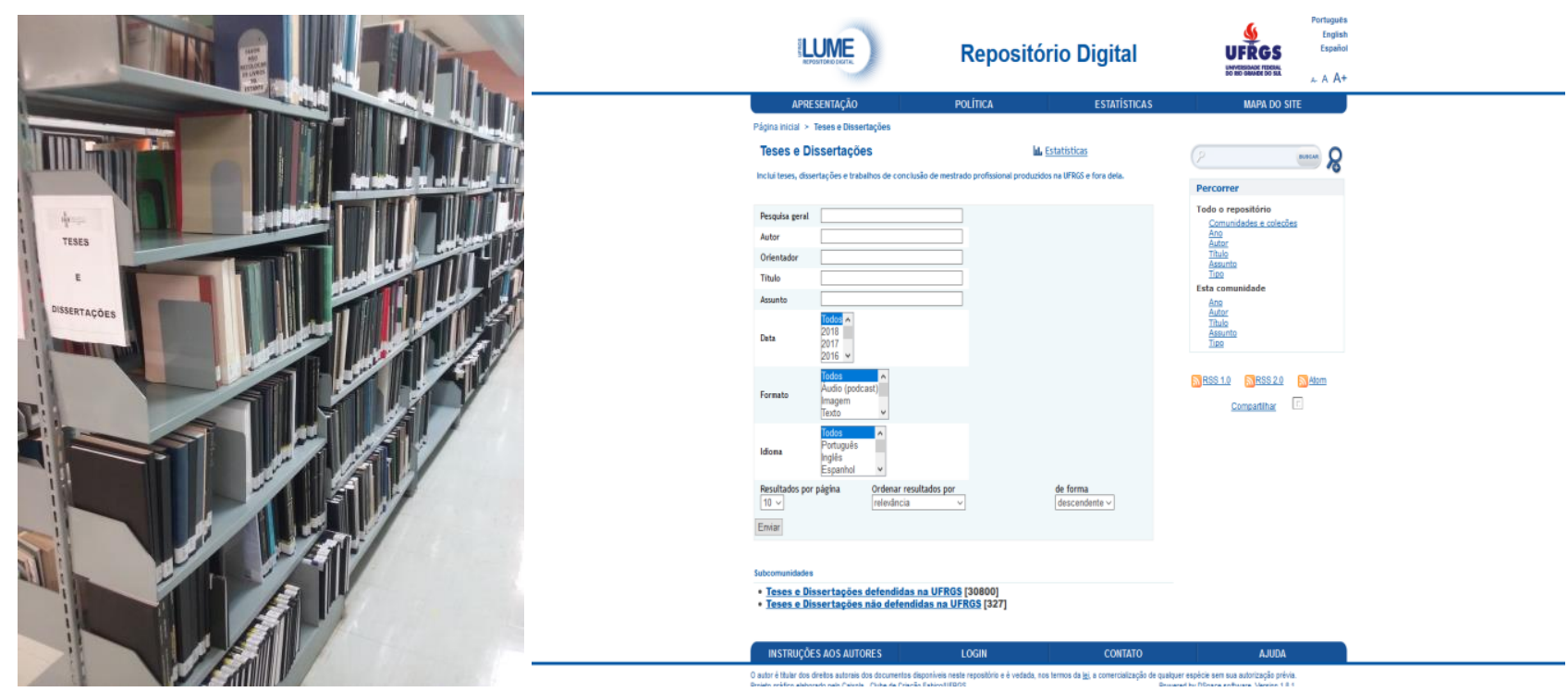

Fonte: do Autor.

Em 2017 o Ranking Web of World repositories, que avalia a relação entre atividade/presença e visibilidade/impacto de produções divulgados na Internet de universidades de todo o mundo, o LUME foi listado como o $2^{\circ}$ melhor repositório do Brasil e da América Latina (atrás apenas da Biblioteca Digital de Teses e Dissertações da USP) e como o $42^{\circ}$ do mundo. 


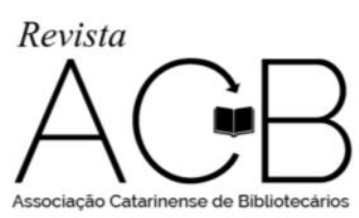

Revista ACB: Biblioteconomia em Santa Catarina, Florianópolis, v. 23, n. 1, p. 21-36, dez./mar., 2018.

\section{METODOLOGIA}

Pesquisa qualitativa do tipo exploratória e bibliográfica quanto aos procedimentos utilizados. Os dados para descreverem o fenômeno das bibliotecas universitárias híbridas como espaços de memória foram buscados junto a bibliografias dos campos da Biblioteconomia, História e Memória Social.

As limitações desta pesquisa são representadas pela heterogeneidade tecnológica em que se apresentam diferentes bibliotecas universitárias tanto nacionais como estrangeiras e a escassa bibliografia sobre o tema delimitado para o estudo.

\section{CONSIDERAÇÕES FINAIS}

A biblioteca como um espaço de preservação do conhecimento humano, naturalmente identifica-se como espaço de memória, uma vez que a biblioteca universitária como guardiã da produção científica, intelectual e cultural das universidades. A preservação do acervo histórico da universidade tem papel fundamental na produção de novos conhecimentos, uma vez que dissemina as informações já existentes.

As bibliotecas universitárias em modelo atual híbrido fomentam o acesso à informação técnicocientífica em quase todos os níveis e distâncias, proporcionando a democratização do saber, como prática social, permitindo o acesso ao conhecimento gerado em suas instituições ao público em geral, que segundo Dodebei (1997) faz com que a biblioteca retome sua condição de locus de memória, de espaço social, em que as trocas culturais acontecem em um plano real de convivência e não somente em um espaço virtual.

As bibliotecas universitárias híbridas, maximizadas pela implantação de repositórios institucionais eletrônicos, hoje permitem uma relevante economia de recursos financeiros e físicos para as instituições acadêmicas, assim como a preservação e promoção da memória das produções geradas em seu âmbito.

Sobre o futuro, Lévy (1999) faz uma previsão em que o ciberespaço será o principal espaço de comunicação e depositário da memória da humanidade quando todas as informações estiverem digitalizadas e acessíveis pelas redes de comunicação. Essa declaração mais do que nunca é um aviso aos espaços de memória, como bibliotecas, museus e arquivos, que estes devem se adaptar aos novos tempos, proporcionando novas formas de reunir, organizar e promover a memória das instituições, das comunidades e dos indivíduos. 


\section{REFERÊNCIAS}

BARBOSA, M.; FRANKLIN, S. Controle, avaliação e qualidade de serviços em unidades de informação. In: LUBISCO, N. (Org.). Biblioteca universitária: elementos para o planejamento, avaliação e gestão. Salvador: UFBA, 2011. p. 89-137.

CARRIÓN GÚTIEZ, A. Las tecnologías de la información y las comunicaciones en las bibliotecas públicas españolas: nuevos usuarios y nuevos servicios. In: FUNDACIÓN GERMÁN SANCHEZ RUIPÉREZ. Las bibliotecas públicas en España. Una realidad abierta. Madrid: Ministerio de Educación, Cultura y Deportes, 2001. Disponível em: 〈http://www.bibliotecaspublicas.info/bp/bp07_1amp.htm>. Acesso em: 10 jun. 2014.

CHAIM, R. M. Estratégias de marketing na internet para websites. In:

AMARAL, Sueli. Marketing na ciência da informação. Brasília, DF: UnB, 2007. p. 97-120.

CHARTIER, R. As revoluções da leitura no Ocidente. In: ABREU, M. (Org.).

Leitura, história e história da leitura. Campinas: Mercado de Letras; Associação de Leitura do Brasil; FAPESP, 2002.

COSTA, I. T. M. Memória institucional: a construção conceitual numa abordagem teóricometodológica. 1997. 169f. Tese (Doutorado)-Universidade Federal do Rio de Janeiro, Rio de Janeiro, 1997.

CRIPPA, G. Memória: geografias culturais entre história e ciência da informação. In: MURGUIA, E. Memória: um lugar de diálogo pra arquivos, bibliotecas e museus. São Carlos: Compacta, 2010.

DODEBEI, V. Cultura Digital: novo sentido e significado de documento para a memória social? DataGramaZero - Revista de Informação, Rio de Janeiro, v. 12, n. 2, 2011. Disponível em: <http://www.dgz.org.br/abr11/Art_01.htm>. Acesso em: 08 mar. 2017.

DODEBEI, V. O sentido e o significado de documento para a memória social. Rio de Janeiro. 1997. 185 f. Tese (Doutorado em Comunicação e Cultura)-Universidade do Rio de Janeiro, Rio de Janeiro, 1997.

FOUCAULT, M. A arqueologia do saber. 5. ed. Rio de Janeiro: Forense Universitaria, 1997.

GARCEZ, E. M. S; RADOS, G. J. V. Biblioteca híbrida: um novo enfoque no suporte a educação à distância. Ciência da Informação, Brasília, DF, v. 31, n. 2, p. 44-51, 2002.

GOULEMOT, J. M. O amor às bibliotecas. São Paulo: UNESP, 2011.

JACOB, C. Prefácio. In: BARATIN, M; JACOB, C. (Org.). O poder das bibliotecas: a memória dos livros no ocidente. Rio de Janeiro: UFRJ, 2000. p. 9-17.

LE COADIC, Y. F. A ciência da informação. 2.ed. Brasília, DF : Briquet de Lemos/Livros, 2004.

LE GOFF, J. Documento/Monumento. In: LE GOFF, J. Memória e história. Campinas: Unicamp, 1990. p. 535-553. 
LE GOFF, J. Memória. In: LE GOFF, J. História e memória. Campinas: Unicamp, 2003.

LEVACOV, M. Do analógico ao digital: a comunicação e a informação no final do milênio. In: LEVACOV, M. (Org.). Tendências na comunicação: cursos de comunicação da PUCRS, UFRGS, ULBRA, UNISINOS. Porto Alegre: L\&PM, 1998. p. 17.

LEVY, P. Cibercultura. São Paulo: Ed. 34, 1999.

MEMÓRIA coletiva. In: E-MNEMON - dicionário de expressões da memória social. Canoas: UNILASALLE, 2011. Disponível em: 〈http://edicionario.unilasalle.edu.br/?p=444>. Acesso em: 08 mar. 2017.

MONTEIRO, S. D.; CARELLI, A. E.; PICKLER, M. E. V. Ciência da informação, memória e esquecimento. DataGramaZero - Revista de Ciência da Informação, Rio de Janeiro, v. 9, n. 6, 2008. Disponível em:

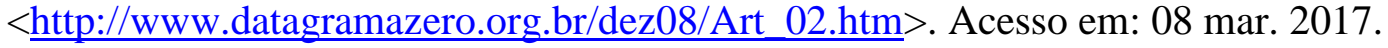

NAMER, G. Instituitions de memoire culturelle. In: NAMER, G. (Org.). Memoire et societé. Paris: Méridien, 1987.

NORA, P. Entre memória e história: a problemática dos lugares. Projeto História, São Paulo, v. 10, p. 7 28, dez. 1993. Disponível em: 〈http://revistas.pucsp.br/index.php/revph/article/view/12101/8763〉. Acesso em: 08 mar. 2017.

OLIVEIRA, E. S; SANTOS, A. E. A. A inutilidade dos lugares de memória: a "Biblioteca Verde" de Carlos Drummond de Andrade. Revista Espaço Acadêmico, Maringá, v. 8, n. 96, 2009. Disponível em: <http://www.espacoacademico.com.br/096/96oliveira-santos.pdf>. Acesso em: 08 mar. 2017.

RIBEIRO, L. B. Memória: um lugar de diálogo para arquivos, bibliotecas e museus. In: MURGUIA, E. Memória: um lugar de diálogo pra arquivos, bibliotecas e museus. São Carlos: Compacta, 2010.

ROWLEY, J. E. A biblioteca eletrônica. Brasília, DF: Briquet de Lemos/Livros, 2002.

RUSBRIDGE, C. Towards the hybrid library. D-Lib Magazine, Reston, v. 4, n. 7/8, 1998. Disponível em: <http://www.dlib.org/dlib/july98/rusbridge/07rusbridge.html>. Acesso em: 30 maio 2014.

SAORÍN PÉREZ, T. El concepto de biblioteca híbrida. Tejuelo, Murcia, n. 2, p. 29-36, 2001. Disponível em: <http://gti1.edu.um.es:8080/saorin/articulos/BHibrida-Tejuelo2001.PDF>. Acesso em: 23 nov. 2014.

SILVEIRA, F. J. N. Sendas entre o visível e o invisível: a biblioteca como "lugar de memória" e de preservação do patrimônio. DataGramaZero - Revista de Informação, Rio de Janeiro, v. 13, n. 5, 2012. Disponível em: 〈http://www.dgz.org.br/out12/Art_03.htm>. Acesso em: 08 mar. 2017.

TAMMARO, A. M.; SALARELLI, A. A biblioteca digital. Brasília, DF: Briquet de Lemos, 2008.

THIESEN, I. Museus arquivos e bibliotecas entre lugares de memória e espaços de produção de conhecimento. In: MUSEU DE ASTRONOMIA E CIÊNCIAS AFINS. Museu e museologia: interfaces e perspectivas. Rio de Janeiro: MAST, 2009. p. 61-82. 


\section{RUBENS DA COSTA SILVA FILHO}

Doutorando em Comunicação e Informação pela Universidade Federal do Rio Grande do Sul (UFRGS). Mestre em Memória Social e Bens Culturais pela Universidade La Salle (UNILASALLE).

Atua como bibliotecário-chefe da Biblioteca da Escola de Enfermagem da Universidade Federal do Rio Grande do Sul (UFRGS).

UFRGS - Biblioteca da Escola de Enfermagem Rua São Manoel, 963, Porto Alegre, RS, Brasil rubens.silva@ufrgs.br 